\title{
Habitual sleep measures are associated with overall body fat, and not specifically with
}

\section{visceral fat in men and women}

Sigrid A Dekker ${ }^{1,2}$, Raymond Noordam ${ }^{1}$, Nienke R Biermasz ${ }^{3}$, Albert de Roos ${ }^{4}$, Hildo J

Lamb $^{4}$, Frits R Rosendaal ${ }^{2,5}$, Patrick CN Rensen ${ }^{3,5}$, Diana van Heemst ${ }^{1}$, Renée de Mutsert ${ }^{2}$

1. Department of Internal Medicine, Section Gerontology and Geriatrics, Leiden University Medical Center, Leiden, the Netherlands

2. Department of Clinical Epidemiology, Leiden University Medical Center, Leiden, the Netherlands

3. Department of Medicine, Division of Endocrinology, Leiden University Medical Center, Leiden, the Netherlands

4. Department of Radiology, Leiden University Medical Center, Leiden, the Netherlands

5. Einthoven Laboratory for Experimental Vascular Medicine, Leiden University Medical Center, Leiden, the Netherlands

Key words: Sleep disorders, abdominal obesity, visceral fat, epidemiology

\section{Address of correspondence}

Raymond Noordam PhD

Department of Internal Medicine, section Gerontology and Geriatrics,

Leiden University Medical Center,

PO Box 9600, 2300 RC Leiden, the Netherlands

Email: r.noordam@lumc.nl

Tel: +31(0)715265213

Fax: +31(0)71526 6912 
Running title: "Sleep and visceral adiposity"

Number of words manuscript: $\quad 3,488$

Number of words abstract: $\quad 195$

Number of tables: $\quad 3$

Number of figures: $\quad 2$

Number of references: $\quad 35$

Number of supplementary tables: 3

\section{Funding}

The NEO study is supported by the participating Departments, the Division and the Board of Directors of the Leiden University Medical Centre, and by the Leiden University, Research Profile Area 'Vascular and Regenerative Medicine'. DvH was supported by the European Commission funded project HUMAN (Health-2013-INNOVATION-1-602757).

\section{Disclosures}

The authors declared no conflict of interest

\section{Author contribution}

Study design: SAD, RN, DvH, RdM. Data analyses: SAD, RN. Data acquisition: NRB, HJL, AdR, FRR, RdM. Overall study design and management: FRR, RdM. Interpretation of the data: $S A D, R N, N R B, P C N R, D v H, R d M$. Drafting the manuscript: SAD, RN. Commenting on the initial versions of the manuscript and final approval for submission: SAD, RN, NRB, AdR, HJL, FRR, PCNR, DvH, RdM. 


\section{What is already known about this subject?}

- Short sleep duration and poor sleep quality are associated with increased body fat.

- Body mass index and waist circumference are poor measures of fat deposition in different compartments.

\section{What does this study add?}

- Short sleep duration and poor sleep quality are associated with a higher amount of visceral adipose tissue in men and women, but this association disappeared after adjustment for total body fat.

- Short sleep duration and poor sleep quality are not specifically associated with a higher amount of visceral adipose tissue. 


\section{Abstract}

Objective: To investigate the associations of sleep duration and sleep quality with visceral adipose tissue (VAT) in middle-aged individuals.

Methods: In this cross-sectional analysis of baseline measurements of the Netherlands Epidemiology of Obesity study, participants underwent anthropometry and completed the Pittsburgh Sleep Quality Index (PSQI) for assessing short sleep duration (as sex-specific ageadjusted percentiles) and poor quality (PSQI $>5$ ). VAT was assessed by magnetic resonance imaging in a random subgroup. We performed linear regression analyses to examine associations of short sleep and poor sleep with measures of body fat, adjusted for confounding including total body fat in models with VAT.

Results: A total of 5,094 participants (52\% women; mean [SD] age of 56 [6] years), of whom 1,947 with VAT, were analyzed. The difference in VAT between poor sleep (PSQI>5) compared to good sleep (PSQI $\leq 5)$ was $7.2(95 \% \mathrm{CI}: 1.2,13.8) \mathrm{cm}^{2}$ in women and 16.1 $\left.(95 \% \mathrm{CI}: 6.2,26.0) \mathrm{cm}^{2}\right)$ in men. These differences attenuated toward the null after the adjustment for total body fat. Similar patterns of associations were observed for short sleep (lowest $10 \%$ as compared to median $60 \%$ ).

Conclusions: Our results suggest that measures of sleep are not specifically associated with a higher amount of VAT. 


\section{Introduction}

Obesity, in particular abdominal obesity, is a well-established risk factor for metabolic and cardiovascular diseases (1). Multiple factors have thus far been identified to contribute to the risk of obesity. In addition to well-known determinants for obesity as a sedentary lifestyle and high caloric intake, broad consensus has been reached in just a few years that short total sleep time and poor sleep quality are associated with a higher body mass index (BMI) $(2,3,4,5,6,7,8,9,10)$. In addition, some of these studies observed an association between long total sleep time and BMI as well, which suggests that there could be a U-shaped relation between total sleep time and BMI $(3,6)$. The hypothesis of a short habitual sleep duration leading to higher body fat is supported by intervention studies. For example, sleep curtailment causes a change in circulating ghrelin and leptin concentrations, hormones essential for sensing hunger and satiety $(11,12)$. Even one night of sleep curtailment causes leptin levels and feeling of satiety to decrease, and ghrelin levels to increase, subsequently increasing the feeling of hunger.

Abdominal adiposity is characterized by storage of excess fat in the abdominal subcutaneous and visceral adipose tissue (VAT). In particular, VAT has been shown to be a strong risk factor for diseases like type 2 diabetes mellitus and cardiovascular diseases $(5,13$, $14,15,16)$. Because direct assessment of VAT by magnetic resonance imaging is not widely available in large cohort studies, studies often investigated the association between sleep duration and waist circumference, as a measure of abdominal adiposity and a proxy of VAT $(3,4,5,17)$. These studies observed that short sleep duration, and not long sleep duration, was associated with a larger waist circumference. The association between poor sleep quality and waist circumference is less well studied, but available literature suggests that poor sleep quality is associated with a higher waist circumference $(18,19)$. 
Waist circumference, however, does not distinguish abdominal subcutaneous fat from visceral fat. Given that VAT is a strong risk factor for insulin resistance $(5,13,14,15,16)$, and different measures of habitual sleep have been associated with insulin resistance and type 2 diabetes mellitus $(20,21,22)$, we hypothesized that short sleep duration as well as poor sleep quality are specifically associated with a higher amount of VAT. Therefore, the aim of this study was to investigate the associations of sleep duration and sleep quality with VAT in a population-based study comprising Dutch middle-aged men and women. 


\section{Methods}

Study design and study population

The present study is a cross-sectional analysis of baseline measurements of the Netherlands Epidemiology of Obesity (NEO) study, a population-based, prospective cohort study. The NEO study started in 2008 and included 6,671 individuals aged 45-65 years, with an oversampling of individuals with overweight or obesity. The study design and population is described in detail elsewhere (23). Men and women living in the greater area of Leiden (in the West of the Netherlands) were invited to participate if they were aged between 45 and 65 years and had a self-reported BMI of $27 \mathrm{~kg} / \mathrm{m}^{2}$ or higher. In addition, all inhabitants aged between 45 and 65 years from one municipality (Leiderdorp) were invited to participate irrespective of their BMI, allowing for a reference group with a normal BMI distribution. The Medical Ethical Committee of the Leiden University Medical Center (LUMC) approved the design of the study. All participants gave their written informed consent.

Participants were invited for a baseline visit at the NEO study centre of the LUMC. Prior to the study visit, participants completed a general questionnaire at home to report demographic, lifestyle and clinical information. Collection of data from the Pittsburgh sleep quality index (PSQI) questionnaire only started as from July 2009. For this reason, participants $(\mathrm{N}=1,402)$ included before July 2009 without PSQI data were not included in the present study. The participants were asked to bring all medication they were using to the study visit for a medication inventory.

At the study site, a screening form was completed by all participants asking about anything that might create a health risk or interfere with MRI imaging (most notably metallic devices, claustrophobia, and a body circumference of more than $1.70 \mathrm{~m}$ ). Of the participants who were eligible for MRI, approximately $35 \%$ of the total study population were randomly selected to undergo direct assessment of VAT. 
Of the participants with PSQI data, participants with missing data on either waist circumference or total body fat $(T B F)(n=30)$ or covariates $(n=145)$ were excluded from the analyses. For the analyses on VAT, only participants with a measurement of VAT were included $(\mathrm{n}=1,947)$.

\section{Assessment of sleep quality and duration}

To assess sleep duration, we made use of the question related to this topic on the Pittsburgh sleep quality index (PSQI) questionnaire: "During the past month, how many hours of actual sleep did you get at night. To facilitate the interpretation of the observations whether there is a non-linear (e.g., U-shape) relationship between sleep duration and measures of adiposity, we studied the associations between sleep duration and measures of adiposity in different strata based on sleep duration. Because there is no consensus in the literature to define short and long total sleep time $(2,3,4,5,6,7,8,9,10,17)$, and defining groups of participants based on the sleep duration could be misclassified because of age and sex, we standardized sleep durations based on the residuals, adjusted for age and stratified by sex. Based on percentiles of these residuals, we defined the shortest sleepers (0-10 percentile), short sleepers (10-20 percentile), middle sleepers (20-80 percentile, reference group), long sleepers (80-90 percentile) and the longest sleepers (90-100 percentile).

Sleep quality was based on the total PSQI score, which ranges from 0 to 21 . A score of $\leq 5$ is considered good sleep quality, whereas a score of $>5$ is considered poor sleep quality (24). In addition, we defined participants with a PSQI score of $\geq 8$ as worse sleep quality.

\section{Measures of body fat}

Body weight and percent body fat were measured by the Tanita bio impedance balance (TBF310, Tanita International Division, UK) without shoes and one kilogram was subtracted to 
correct for the weight of clothing. Height was measured without shoes with a vertically fixed, calibrated tape measure. BMI was calculated by dividing the weight in kilograms by the height in meters squared. Waist circumference was measured with a horizontally placed tape measure mid-way between the lower costal margin and the iliac crest with a precision of 0.1 $\mathrm{cm}$.

Abdominal subcutaneous and visceral fat were quantified by a turbo spin echo imaging protocol using MRI in 1,947 participants with exposure and covariate data. Imaging was performed on a 1.5 Tesla MR system (Philips Medical Systems, Best, the Netherlands). The VAT depots was quantified by converting the number of pixels to square $\mathrm{cm}$ for all three slides using in-house-developed software (MASS, Medis, Leiden, the Netherlands). At the level of the $5^{\text {th }}$ lumbar vertebra three transverse images each with a slice thickness of $10 \mathrm{~mm}$ were obtained during a breath-hold. The mean of VAT from the three slices was calculated and used in the analyses.

\section{Covariates}

Based on questionnaires, participants reported ethnicity by self-identification in eight categories which we grouped into white and other. Tobacco smoking was reported in the three categories: current smoker, former smoker, or never smoker. Highest level of education was reported in 10 categories according to the Dutch education system and participants with none, primary school or lower vocational education were categorized as lower educated and the others as higher educated. Alcohol and coffee consumption were self-reported on a food frequency questionnaire. Alcohol consumption was expressed in grams of alcohol per day and coffee consumption as cups per day. Participants reported the frequency, duration and intensity of their usual physical activity during leisure times using the Short Questionnaire to Assess Health-enhancing physical activity $(\operatorname{SQUASH})(25,26)$. For this questionnaire, 
participants reported the frequency and duration of their physical activity during leisure time and this was expressed in hours per week of metabolic equivalents. Menopausal status was divided into three categories (pre-, peri-, and postmenopausal) based on information on oopho- or hysterectomy and/or self-reported menopausal status. Women who reported a hysterectomy were classified according to their age (premenopausal when $<46$ years, perimenopausal when 46 to 55 years, and postmenopausal when $\geq 55$ years). Women who did not report menopausal status and were 58 years or older were classified as postmenopausal. Use of hormones (hormone replacement therapy and oral contraceptives) and of sleep medication was based on a medication inventory.

\section{Statistical analysis}

In the NEO study, persons with a BMI of $27 \mathrm{~kg} / \mathrm{m}^{2}$ or higher are oversampled. To correctly represent associations for the general population (27), adjustments for the oversampling of participants with a BMI $\geq 27 \mathrm{~kg} / \mathrm{m}^{2}$ are made. This is done by weighting individuals towards the BMI distribution of participants from the Leiderdorp municipality (28), whose BMI distribution was similar to the BMI distribution of the general Dutch population (29). All results are based on weighted analyses. Consequently, the results apply to a population-based study without oversampling of individuals with a BMI $\geq 27 \mathrm{~kg} / \mathrm{m}^{2}$. All analyses are performed using STATA version 12.1 (StataCorp LP, TX, US).

Baseline characteristics of the study population were expressed as mean (with standard deviation $[\mathrm{SD}]$ ), median (inter quartile range [IQR]) or proportion $(\%)$, in the whole study population and separately for men and women (Table 1). Given the known differences in body fat distribution and habitual sleep between men and women, all analyses were performed separately for men and women. In the first analyses, we aimed to confirm wellestablished associations between short habitual sleep duration and poor sleep quality and 
BMI, waist circumference and total body fat in the total study population $(2,3,4,5,6,7,8,9$, 10). Subsequently, we repeated these analyses for the subpopulation of participants who underwent MRI, and investigated the association between short habitual duration and poor sleep quality and VAT. To examine the associations between sleep duration and the measures of adiposity, we performed multivariable linear regression analyses. We calculated the mean difference in adiposity measure in the sleep duration groups and sleep quality groups compared with the reference groups $(20-80 \%$ middle sleep duration and PSQI $\leq 5)$ with corresponding 95\% confidence intervals. We adjusted crude models for age, physical activity, menopausal state, ethnicity, alcohol consumption, coffee consumption, smoking, education and the use of oral contraceptives and hormone replacement therapy (ATC-code: G03A, G03C, G03F). The models of sleep duration were additionally adjusted for sleep medication (ATC-code: N05C) use. We additionally performed joint models and adjusted the analyses of sleep duration for sleep quality and vice versa to provide insights on the relative contributions of these two measures of habitual sleep to the measures of adiposity. We adjusted the analyses concerning VAT for TBF to investigate to what extent associations were specific for VAT instead of merely a reflection of associations with overall adiposity. Finally, we tested whether the associations between habitual sleep and measures of adiposity were different between men and women by including an interaction term between sex and the measure of habitual sleep in the fully adjusted models. 


\section{Results}

Characteristics of the study population

A total of 5,094 participants completed the PSQI-questionnaire and had complete data on potential confounding factors. Of these, VAT was assessed in 1,947 participants. In the total study population (54\% women) (Table 1), mean (SD) age was 55.7 (6.0) years.

Mean (SD) sleep duration was 7.1 (1.0) hours in women and 6.9 (1.0) hours in men. PSQI score had a median (IQR) of $5(3,7)$ in women and $4(2,5)$ in men. Whereas women had more total body fat than men, men had a larger waist circumference and more VAT than women. The characteristics of the subpopulation with VAT assessment were similar to the total study population (Supplement Table 1).

\section{Associations between sleep duration and measures of adiposity}

Compared with the reference population (Table 2), we observed that both in men and women the group of the shortest sleepers had a higher BMI (mean difference [ $95 \%$ confidence interval] in women $1.9[1.0,2.9] \mathrm{kg} / \mathrm{m}^{2}$; in men $\left.1.3[0.6,2.0] \mathrm{kg} / \mathrm{m}^{2}\right)$, larger waist circumference (women $4.2[1.6,6.8] \mathrm{cm}$, men $3.9[1.9,6.0] \mathrm{cm}$ ) and more TBF (women 2.3 $[0.9,3.6] \%$, men $1.7[0.6,2.9] \%)$. These results did not materially differ when we adjusted for potential confounding factors. Additional adjustment for sleep quality only slightly attenuated the associations (results not shown). Compared with the reference population, short, long and longest sleep were not associated with BMI, waist circumference or TBF. We observed similar associations for BMI, waist circumference and TBF in the subpopulation of participants who underwent MRI (Supplementary Table 2).

Compared with the reference group (Figure 1), the shortest sleep group had more VAT (women $16.4[3.1,29.8] \mathrm{cm}^{2}$, men $10.2[-4.1,24.2] \mathrm{cm}^{2}$ ). However, additional adjustment of the associations for TBF, attenuated the estimates for shortest sleep duration 
towards the null (women $6.4[-1.4,14.1] \mathrm{cm}^{2}$, men $0.6[-10.8,12.0] \mathrm{cm}^{2}$ ). No evidence was observed for differences between men and women (P-value for interaction $>0.05)$.

Associations between sleep quality and measures of adiposity

Table 3 shows the mean differences in BMI, waist circumference and TBF associated with the sleep quality groups (poor sleep quality PSQI >5; worse sleep quality PSQI $\geq 8$ ) compared with the reference group (PSQI $\leq 5)$. In crude models, poor sleep quality was associated with higher BMI (women $0.8[0.4,1.2] \mathrm{kg} / \mathrm{m}^{2}$, men $0.7[0.3,1.2] \mathrm{kg} / \mathrm{m}^{2}$ ), larger waist circumference (women $1.8[0.6,3.1] \mathrm{cm}$, men $2.5[1.2,3.8] \mathrm{cm}$ ) and more TBF (women 1.1 $[0.4,1.8] \%$, men $1.1[0.4,1.8] \%)$. In line, worse sleep quality (PSQI $\geq 8$ ) was associated with higher BMI (women $1.1[0.6,1.6] \mathrm{kg} / \mathrm{m}^{2}$, men $0.8[0.1,1.4] \mathrm{kg} / \mathrm{m}^{2}$ ), larger waist circumference (women $2.7[1.1,4.2] \mathrm{cm}$, men $2.6[0.7,4.4] \mathrm{cm}$ ) and more TBF (women 1.7 $[0.8,2.5] \%$, men $1.3[0.3,2.3] \%)$. These associations attenuated after adjustment for potential confounding factors. Additional adjustment for sleep duration did not notably change the associations (results not shown). We observed similar associations for BMI, waist circumference and TBF in the subpopulation of participants who underwent MRI (Supplementary Table 3).

Compared with normal sleep (PSQI $\leq 5)$, poor sleep quality was associated with more VAT in men $\left(17.5 \mathrm{~cm}^{2}[7.2,27.8]\right)$ and women $\left(7.5 \mathrm{~cm}^{2}[1.2,13.8]\right)$; estimates did not materially change after adjustment for potential confounding factors with the exception of TBF (Figure 2). Associations of worse sleep were in similar direction as compared with normal sleep, although with larger confidence intervals (women $9.3 \mathrm{~cm}^{2}$ [1.2, 17.4]; men 9.1 $\left.\mathrm{cm}^{2}[-3.5,21.8]\right)$. After additional adjustment for TBF the associations attenuated toward the null (poor quality: women $-1.4[-5.9,3.1] \mathrm{cm}^{2}$, men $6.5[-1.6,14.5] \mathrm{cm}^{2}$; worse quality: 
women -2.2 [-7.9, 3.5] $\mathrm{cm}^{2}$, men $2.3[-6.7,11.2] \mathrm{cm}^{2}$ ) (Figure 2). No evidence was observed for differences between men and women (P-value for interaction $>0.05)$. 


\section{Discussion}

In the present population-based study of middle-aged men and women, we observed that short sleep duration and poor sleep quality were associated with measures of overall and abdominal adiposity, but we did not observe a clear dose-response relationship between sleep quality and abdominal adiposity. However, associations of sleep quality and duration with visceral fat disappeared after adjustment for TBF. These results suggest that, although measures of sleep were associated with TBF and other measures of overall adiposity, short habitual sleep duration and quality were not specifically associated with VAT. These results were similarly observed for men and women.

The observed associations with BMI, waist circumference and TBF are consistent with other observational studies, showing that short sleep duration and poor sleep quality are associated with having more body fat $(2,3,4,5,6,7,8,9,10)$. Besides the observation that men and women have different sleeping habits (women tend to sleep longer, and have a higher risk of experiencing insomnia during their lifespan, and 33-51\% of women report sleep complaints during menopausal transition (30)), and have a different body fat distribution, the observed associations of sleep duration and sleep quality with adiposity were similar in men and women. The observation that the association of short sleep duration and poor sleep quality with VAT attenuated after adjustment for TBF, is in line with a crosssectional study performed in a Japanese population (31). In 5,400 Japanese men with selfreported sleep data, and computed tomography data to determine body fat depots, short sleep duration was associated with higher BMI, waist circumference, abdominal subcutaneous adipose tissue and VAT. However, when the association with VAT was adjusted for abdominal subcutaneous adipose tissue, this association disappeared, which is consistent with our findings. While we observed an association between short sleep duration and adiposity in 
both men and women, there was no association in Japanese women, although this discrepance in results could also be due to a limited sample size $(n=642)(31)$.

Our results suggest that a habitual short sleep duration and poor sleep quality are associated with general adiposity rather than abdominal adiposity. A possible reason for the lack of an association between sleep and VAT independent of total body fat could be either explained by a too low number of individuals classified as short sleeper or that the association between sleep measures and VAT does not exist independent of overall adiposity. Furthermore, the group classified as short sleepers reported a sleep duration ranging between 1.7 and 5.7 hours. However, as there is no consensus about the definition of short sleep $(2,3$, $4,5,6,7,8,9,10,17)$, we are not able to determine whether the total sleep duration in this group is sufficiently short to observe any associations. Unlike some of the previous studies $(3,6)$, we did not observe a U-shape between sleep duration and adiposity in this population. One potential explanation could be that sleep was not sufficiently long in the percentiles which we defined as long sleep (sleep duration in the upper percentile ranged between 8 and 13 hours). Although we classified the highest percentile as long sleep duration; the sleep duration reported by this group still only ranged between 8.0 and 13.0 hours. As there is no consensus about the definition of long sleep $(2,3,4,5,6,7,8,9,10,17)$, it is unclear whether this group includes a sufficient number of long sleepers. Also, the majority of the other studies did not observe a U-shape $(2,4,5,7,8,9,10)$. Therefore, it is possible that the few (smaller) studies that observed this U-shape found a false-positive association between long sleep and increased adiposity.

One of the strengths of our study is the direct assessment of visceral fat with MRI (32) in a relatively large study population. A limitation of this study is its cross-sectional and observational design. As a result, we cannot draw conclusions on the direction and causality of the associations between measures of sleep and adiposity. In literature, evidence for both 
directions is described. It has been shown that even one night of sleep deprivation can lead to decreased leptin levels, and increased ghrelin levels, which subsequently increase appetite $(11,12)$. Furthermore, a recent genome-wide association study on different measures of habitual sleep found a shared genetic component of insomnia symptoms and obesity risk (33). However, obesity has also been described as an important risk factor for multiple sleeping disorders, which includes sleep apnea $(34,35)$. Another limitation is that sleep data was selfreported, and objective sleep measurements with actigraphy or polysomnography may be more reliable methods to assess sleep duration and quality. Other studies have investigated the association between objective sleep measures and adiposity. For example, Moraes et al.(4) used both actigraphy and polysomnography to assess sleep duration. Also they observed an association between short sleep duration, measured by both actigraphy and polysomnography, and increased adiposity. And last, this study was done in a study population predominantly of European ancestry. For this reason, our results need to be confirmed in populations of different ancestry backgrounds. However, in the Multi-Ethnic Study of Atherosclerosis (MESA) study short sleep duration ( $<6$ hours) was associated with higher BMI, waist circumference and TBF, also after adjustment for race, and there was no evidence for effect modification by race (10).

Taken together, both short sleep duration and poor sleep quality are associated with more overall body fat in middle-aged men and women and these associations were not specific for VAT. The previously observed associations between disturbances in measures of habitual sleep (e.g., short sleep duration, poor sleep quality) and insulin resistance and type 2 diabetes mellitus $(20,21,22)$ is therefore not likely to be specifically affected by higher amounts of VAT in individuals with short sleep duration and poor sleep quality. Future prospective studies should investigate the direction of the associations between sleep duration and quality with overall body fat in longitudinal studies. 


\section{Acknowledgements}

We express our gratitude to all individuals who participate in the Netherlands Epidemiology in Obesity study. We are grateful to all participating general practitioners for inviting eligible participants. We furthermore thank P.R. van Beelen and all research nurses for collecting the data and P.J. Noordijk and her team for sample handling and storage and I. de Jonge, MSc for data management of the NEO study. 


\section{References}

1. Dale CE, Fatemifar G, Palmer TM, White J, Prieto-Merino D, Zabaneh D, et al. Causal Associations of Adiposity and Body Fat Distribution With Coronary Heart Disease, Stroke Subtypes, and Type 2 Diabetes Mellitus: A Mendelian Randomization Analysis. Circulation 2017;135: 2373-2388.

2. Cappuccio FP, Taggart FM, Kandala N-B, Currie A, Peile E, Stranges S, et al. MetaAnalysis of Short Sleep Duration and Obesity in Children and Adults. Sleep 2008;31: 619-626.

3. Lopez-Garcia E, Faubel R, Leon-Munoz L, Zuluaga MC, Banegas JR, RodriguezArtalejo F. Sleep duration, general and abdominal obesity, and weight change among the older adult population of Spain. The American journal of clinical nutrition 2008;87: 310-316.

4. Moraes W, Poyares D, Zalcman I, de Mello MT, Bittencourt LR, Santos-Silva R, et al. Association between body mass index and sleep duration assessed by objective methods in a representative sample of the adult population. Sleep medicine 2013;14: $312-318$

5. Theorell-Haglow J, Berne C, Janson C, Sahlin C, Lindberg E. Associations between short sleep duration and central obesity in women. Sleep 2010;33: 593-598. 
6. van den Berg JF, Knvistingh Neven A, Tulen JH, Hofman A, Witteman JC, Miedema HM, et al. Actigraphic sleep duration and fragmentation are related to obesity in the elderly: the Rotterdam Study. International journal of obesity (2005) 2008;32: 1083 1090.

7. Watson NF, Buchwald D, Vitiello MV, Noonan C, Goldberg J. A Twin Study of Sleep Duration and Body Mass Index. Journal of Clinical Sleep Medicine : JCSM : Official Publication of the American Academy of Sleep Medicine 2010;6: 11-17.

8. Madrid-Valero JJ, Martinez-Selva JM, Ordonana JR. Sleep quality and body mass index: a co-twin study. Journal of sleep research 2017.

9. Hinz A, Glaesmer H, Brahler E, Loffler M, Engel C, Enzenbach C, et al. Sleep quality in the general population: psychometric properties of the Pittsburgh Sleep Quality Index, derived from a German community sample of 9284 people. Sleep medicine 2017;30: 57-63.

10. Ogilvie RP, Redline S, Bertoni AG, Chen X, Ouyang P, Szklo M, et al. Actigraphy Measured Sleep Indices and Adiposity: The Multi-Ethnic Study of Atherosclerosis (MESA). Sleep 2016;39: 1701-1708.

11. Spiegel K, Tasali E, Penev P, Van Cauter E. Brief communication: Sleep curtailment in healthy young men is associated with decreased leptin levels, elevated ghrelin 
levels, and increased hunger and appetite. Annals of internal medicine 2004;141: 846850.

12. Taheri S, Lin L, Austin D, Young T, Mignot E. Short sleep duration is associated with reduced leptin, elevated ghrelin, and increased body mass index. PLoS medicine 2004;1: e62.

13. Tchernof A, Despres JP. Pathophysiology of human visceral obesity: an update. Physiological reviews 2013;93: 359-404.

14. Liu R, Zee PC, Chervin RD, Arguelles LM, Birne J, Zhang S, et al. Short sleep duration is associated with insulin resistance independent of adiposity in Chinese adult twins. Sleep medicine 2011;12: 914-919.

15. Kaess BM, Pedley A, Massaro JM, Murabito J, Hoffmann U, Fox CS. The ratio of visceral to subcutaneous fat, a metric of body fat distribution, is a unique correlate of cardiometabolic risk. Diabetologia 2012;55: 2622-2630.

16. Grandner MA, Seixas A, Shetty S, Shenoy S. Sleep Duration and Diabetes Risk: Population Trends and Potential Mechanisms. Current diabetes reports 2016;16: 106.

17. Sperry SD, Scully ID, Gramzow RH, Jorgensen RS. Sleep Duration and Waist Circumference in Adults: A Meta-Analysis. Sleep 2015;38: 1269-1276. 
18. Moreno-Vecino B, Arija-Blazquez A, Pedrero-Chamizo R, Gomez-Cabello A, Alegre LM, Perez-Lopez FR, et al. Sleep disturbance, obesity, physical fitness and quality of life in older women: EXERNET study group. Climacteric : the journal of the International Menopause Society 2017;20: 72-79.

19. Xiao Q, Gu F, Caporaso N, Matthews CE. Relationship between sleep characteristics and measures of body size and composition in a nationally-representative sample. BMC obesity 2016;3: 48.

20. Wu Y, Zhai L, Zhang D. Sleep duration and obesity among adults: a meta-analysis of prospective studies. Sleep Med 2014;15: 1456-1462.

21. Xi B, He D, Zhang M, Xue J, Zhou D. Short sleep duration predicts risk of metabolic syndrome: a systematic review and meta-analysis. Sleep Med Rev 2014;18: 293-297.

22. Javaheri S, Storfer-Isser A, Rosen CL, Redline S. Association of short and long sleep durations with insulin sensitivity in adolescents. J Pediatr 2011;158: 617-623.

23. de Mutsert R, den Heijer M, Rabelink TJ, Smit JW, Romijn JA, Jukema JW, et al. The Netherlands Epidemiology of Obesity (NEO) study: study design and data collection. European journal of epidemiology 2013;28: 513-523. 
24. Buysse DJ, Reynolds CF, 3rd, Monk TH, Berman SR, Kupfer DJ. The Pittsburgh Sleep Quality Index: a new instrument for psychiatric practice and research. Psychiatry research 1989;28: 193-213.

25. de Hollander EL, Zwart L, de Vries SI, Wendel-Vos W. The SQUASH was a more valid tool than the OBiN for categorizing adults according to the Dutch physical activity and the combined guideline. Journal of clinical epidemiology 2012;65: 73-81.

26. Wendel-Vos GC, Schuit AJ, Saris WH, Kromhout D. Reproducibility and relative validity of the short questionnaire to assess health-enhancing physical activity. Journal of clinical epidemiology 2003;56: 1163-1169.

27. Korn EL, Graubard BI. Epidemiologic studies utilizing surveys: accounting for the sampling design. American journal of public health 1991;81: 1166-1173.

28. Lumley T. Analysis of complex survey samples.

http://www.jstatsoft.org/v09/i08/paper 2004 [accessed 02.05.13] [cited 2013 02/05]. Available from: http://www.jstatsoft.org/v09/i08/paper.

29. Ministerie van VWS. NdMG. Hoeveel mensen hebben overgewicht? 2013 [accessed 02.05.13] [cited 2013 02/05]. Available from:

http://www.rivm.nl/dsresource?objectid=rivmp:76024\&type=org\&disposition=inline $\underline{\text { \&ns nc }}=1$. 
30. Mong JA, Cusmano DM. Sex differences in sleep: impact of biological sex and sex steroids. Philosophical Transactions of the Royal Society B: Biological Sciences $2016 ; 371$.

31. Yi S, Nakagawa T, Yamamoto S, Mizoue T, Takahashi Y, Noda M, et al. Short sleep duration in association with CT-scanned abdominal fat areas: the Hitachi Health Study. Int J Obes 2013;37: 129-134.

32. Neamat-Allah J, Wald D, Hüsing A, Teucher B, Wendt A, Delorme S, et al. Validation of Anthropometric Indices of Adiposity against Whole-Body Magnetic Resonance Imaging - A Study within the German European Prospective Investigation into Cancer and Nutrition (EPIC) Cohorts. PLOS ONE 2014;9: e91586.

33. Lane JM, Liang J, Vlasac I, Anderson SG, Bechtold DA, Bowden J, et al. Genomewide association analyses of sleep disturbance traits identify new loci and highlight shared genetics with neuropsychiatric and metabolic traits. Nature genetics 2017;49: 274-281.

34. Schwartz AR, Patil SP, Laffan AM, Polotsky V, Schneider H, Smith PL. Obesity and obstructive sleep apnea: pathogenic mechanisms and therapeutic approaches. Proceedings of the American Thoracic Society 2008;5: 185-192. 
35. Carter R, III, Watenpaugh DE. Obesity and obstructive sleep apnea: Or is it OSA and obesity? Pathophysiology;15: 71-77. 


\section{FIGURE LEGENDS}

Figure 1: Associations between sleep duration and VAT in 1947 participants in the NEO study aged between 45 and 65 years.

Results were based on analyses weighted towards the BMI distribution of the general population ( $\mathrm{n}=1947 ; 1032$ men, 915 women). Results van be interpreted as the mean difference (with 95\% confidence interval) in VAT (in $\mathrm{cm}^{2}$ ) between the index and reference group. Model 1, crude model. Model 2, adjusted for age, physical activity, education, ethnicity, alcohol consumption, coffee consumption, and smoking. Model 3, Model $2+$ total body fat. Models 2 and 3 in women were additionally adjusted for menopausal status and the use of hormones.

Figure 2: Associations between sleep quality and VAT in 1947 participants in the NEO study aged between 45 and 65 years.

Results were based on analyses weighted towards the BMI distribution of the general population ( $\mathrm{n}=1947 ; 1032$ men, 915 women). Results van be interpreted as the mean difference (with $95 \%$ confidence interval) in VAT (in $\mathrm{cm}^{2}$ ) between the index and reference group. Model 1, unadjusted for potential confounding factors. Model 2, adjusted for age, physical activity, education, ethnicity, alcohol consumption, coffee consumption, and smoking. Model 3, Model $2+$ total body fat. Models 2 and 3 in women were additionally adjusted for menopausal status and the use of hormones. 
Table 1: Characteristics of the participants in the Netherlands Epidemiology of Obesity study, and stratified by sex.

\begin{tabular}{|c|c|c|c|}
\hline Characteristics & Total population & $\begin{array}{c}\text { Women } \\
(56 \%)\end{array}$ & $\begin{array}{c}\text { Men } \\
(44 \%)\end{array}$ \\
\hline Age (years), mean (SD) & $56(6)$ & $55.5(6)$ & $56(6)$ \\
\hline BMI $\left(\mathrm{kg} / \mathrm{m}^{2}\right)$, mean $(\mathrm{SD})$ & $26.0(4)$ & $25.6(5)$ & $27(4)$ \\
\hline Total body fat (\%),mean (SD) & $31(9)$ & $36.4(7)$ & $25(6)$ \\
\hline Waist circumference $(\mathrm{cm})$, mean $(\mathrm{SD})$ & $91(13)$ & $86(13)$ & $98(11)$ \\
\hline $\operatorname{VAT}\left(\mathrm{cm}^{2}\right)(\mathrm{n}=1947)$, median $(\mathrm{SD})$ & $76(47,116)$ & $54(36,84)$ & $101(73,140)$ \\
\hline Total sleep duration (hours/night), mean (SD) & $7(1)$ & $7(1)$ & $7(1)$ \\
\hline Pittsburgh score, median (IQR) & $4(3,6)$ & $5(3,7)$ & $4(2,5)$ \\
\hline Education (high ${ }^{a}$ ), \% & $47 \pm 1.4$ & $45 \pm 1.9$ & $49 \pm 2.0$ \\
\hline Ethnicity (white), \% & $95 \pm 0.6$ & $95 \pm 0.8$ & $95 \pm 0.9$ \\
\hline Alcohol consumption (grams/day), median (IQR) & $10(3,21)$ & $8(2,15)$ & $17(6,28)$ \\
\hline Physical activity (MET-hours/week), median (IQR) & $30(16,50)$ & $30(17,49)$ & $31(16,51)$ \\
\hline \multicolumn{4}{|l|}{ Coffee consumption ${ }^{\mathrm{b}}, \%$} \\
\hline 0 cups/day & $5 \pm 0.6$ & $7 \pm 1.0$ & $2 \pm 0.6$ \\
\hline$>0-4 \mathrm{cups} /$ day & $61 \pm 1.3$ & $68 \pm 1.8$ & $52 \pm 2.0$ \\
\hline$>4$ cups/day & $34 \pm 1.3$ & $25 \pm 1.7$ & $46 \pm 2.0$ \\
\hline \multicolumn{4}{|l|}{ Smoking, $\%$} \\
\hline Current & $16 \pm 1.0$ & $15 \pm 1.4$ & $18 \pm 1.5$ \\
\hline Former & $45 \pm 1.4$ & $44 \pm 1.9$ & $46 \pm 2.0$ \\
\hline Use of hypnotics and sedatives, $\%$ & $4 \pm 0.5$ & $5 \pm 0.8$ & $2 \pm 0.6$ \\
\hline \multicolumn{4}{|l|}{ Hormone use ${ }^{c}, \%$} \\
\hline Current & & $10 \pm 1.1$ & - \\
\hline Former & & $81 \pm 1.5$ & - \\
\hline Post-menopausal state, $\%$ & & $60 \pm 1.9$ & - \\
\hline
\end{tabular}

Results were based on analyses weighted towards the BMI distribution of the general population ( $\mathrm{n}=5094 ; 2449$ men and 2645 women). Data are shown as mean (SD), median (IQR) or percentage $\pm 95 \%$ confidence interval for measurement dispersion.

BMI: Body Mass Index; NEO: Netherlands Epidemiology of Obesity; VAT: visceral adipose tissue; MET: metabolic equivalent.

${ }^{a}$ High education: higher general secondary education, pre-university education, higher vocational education, university.

${ }^{\mathrm{b}}$ Coffee cup defined as $125 \mathrm{ml} / \mathrm{cup}$. 
${ }^{\mathrm{c}}$ Hormone use: use of sex hormones, as taken by oral contraceptives or hormone replacement therapy. 
Table 2: Associations between sleep duration and BMI, WC and TBF in 5094 participants in the NEO study aged between 45 and 65 years

\begin{tabular}{|c|c|c|c|c|c|}
\hline & $\begin{array}{c}\text { Shortest sleep } \\
(0-10 \%) \\
\text { Men }=1.7-5.7 \mathrm{hrs} \\
\text { Women }=2.5-5.4 \mathrm{hrs} \\
\end{array}$ & $\begin{array}{c}\text { Short sleep } \\
(10-20 \%) \\
\text { Men }=5.7-6.0 \mathrm{hrs} \\
\text { Women }=5.4-5.9 \mathrm{hrs}\end{array}$ & $\begin{array}{c}\text { Reference } \\
(20-80 \%) \\
\text { Men }=6.0-7.7 \mathrm{hrs} \\
\text { Women }=5.9-7.9 \mathrm{hrs} \\
\end{array}$ & $\begin{array}{c}\text { Long sleep } \\
(80-90 \%) \\
\text { Men }=7.7-8.0 \mathrm{hrs} \\
\text { Women }=7.9-8.0 \mathrm{hrs}\end{array}$ & $\begin{array}{c}\text { Longest sleep } \\
(90-100 \%) \\
\text { Men }=8.0-13.0 \mathrm{hrs} \\
\text { Women }=8.0-12.9 \mathrm{hrs}\end{array}$ \\
\hline \multicolumn{6}{|c|}{ Body mass index $\left(\mathrm{kg} / \mathrm{m}^{2}\right)$} \\
\hline Men, model 1 & $1.3(0.6,2.0)$ & $-0.1(-0.7,0.6)$ & - & $0.2(-0.5,0.8)$ & $-0.2(-0.8,0.6)$ \\
\hline Men, model 2 & $1.2(0.5,1.8)$ & $-0.1(-0.7,0.5)$ & - & $0.2(-0.4,0.9)$ & $-0.4(-1.1,0.3)$ \\
\hline Women, model 1 & $1.9(1.0,2.9)$ & $0.5(-0.3,1.3)$ & - & $0.2(-0.5,0.9)$ & $0.2(-0.5,1.1)$ \\
\hline Women, model 2 & $1.6(0.7,2.6)$ & $0.4(-0.4,1.2)$ & - & $0.1(-0.7,0.8)$ & $0.2(-0.6,1.0)$ \\
\hline \multicolumn{6}{|c|}{ Waist circumference $(\mathrm{cm})$} \\
\hline Men, model 1 & $3.9(1.9,6.0)$ & $-0.2(-2.2,1.7)$ & - & $0.4(-1.6,2.4)$ & $0.0(-2.1,2.1)$ \\
\hline Men, model 2 & $3.4(1.5,5.4)$ & $-0.5(-2.5,1.4)$ & - & $0.7(-1.2,2.5)$ & $-0.6(-2.6,1.4)$ \\
\hline Women, model 1 & $4.2(1.6,6.8)$ & $1.8(-0.3,4.0)$ & - & $0.1(-1.8,2.1)$ & $1.4(-0.8,3.6)$ \\
\hline Women, model 2 & $3.6(1.0,6.2)$ & $1.3(-1.0,3.5)$ & - & $0.1(-1.9,2.1)$ & $1.4(-0.8,3.6)$ \\
\hline \multicolumn{6}{|l|}{ Total body fat (\%) } \\
\hline Men, model 1 & $1.7(0.6,2.9)$ & $0.0(-1.0,1.1)$ & - & $-0.1(-1.2,1.1)$ & $-0.1(-1.2,1.1)$ \\
\hline Men, model 2 & $1.4(0.3,2.5)$ & $-0.2(-1.3,0.8)$ & - & $-0.1(-1.2,0.9)$ & $-0.5(-1.6,0.7)$ \\
\hline Women, model 1 & $2.3(0.9,3.6)$ & $0.8(-0.6,2.2)$ & - & $-0.2(-1.4,1.0)$ & $0.6(-0.8,1.9)$ \\
\hline Women, model 2 & $1.9(0.6,3.3)$ & $0.5(-0.9,1.8)$ & - & $-0.2(-1.5,1.1)$ & $0.5(-0.9,1.9)$ \\
\hline
\end{tabular}

Results are presented as the mean differences (with $95 \%$ confidence interval) compared with the reference group, and based on analyses

weighted towards the BMI distribution of the general population ( $\mathrm{n}=5094 ; 2449$ men and 2645 women). Model 1, crude model. Model 2 ,

adjusted for age, physical activity, education, ethnicity, use of hypnotics and sedatives, alcohol consumption, coffee consumption and smoking.

Analyses in women were additionally adjusted for menopausal status and use of hormones. 
Table 3: Associations between sleep quality and BMI, WC and TBF in 5094 participants in the NEO study aged between 45 and 65 years.

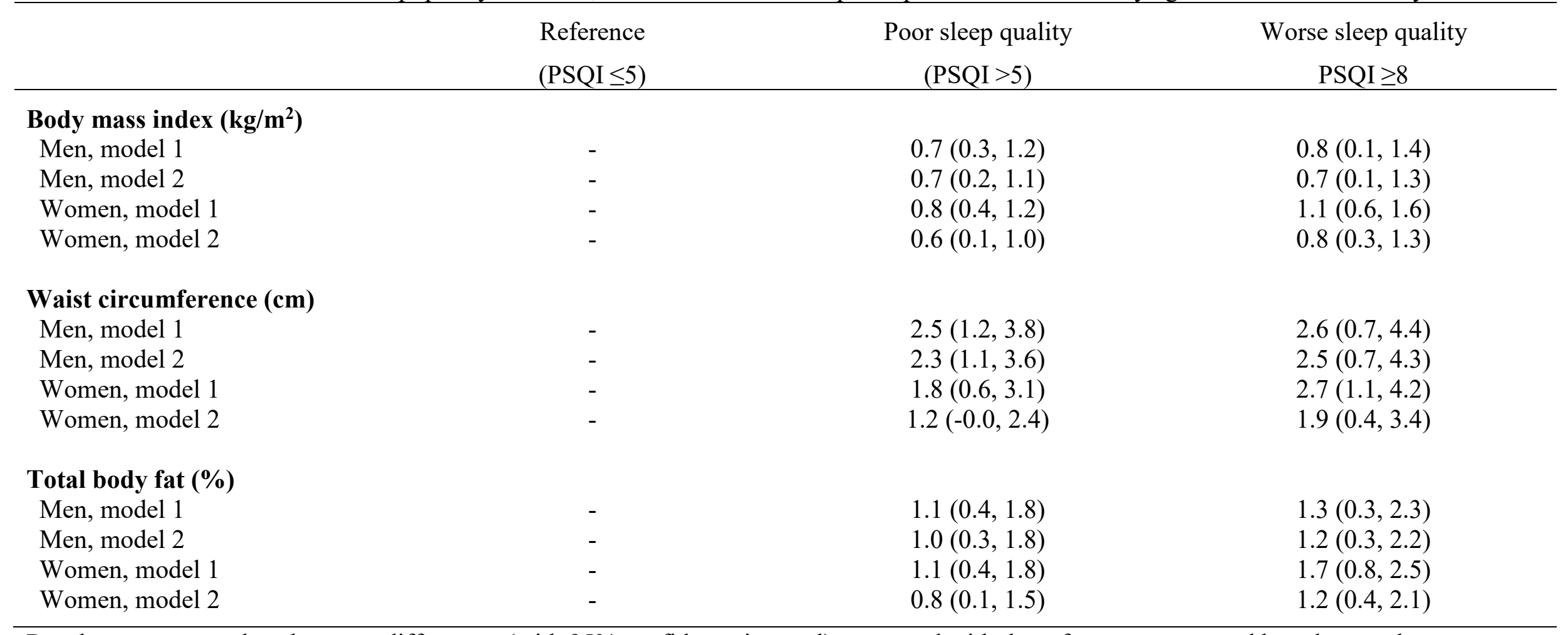

Results are presented as the mean differences (with 95\% confidence interval) compared with the reference group, and based on analyses

weighted towards the BMI distribution of the general population ( $\mathrm{n}=5094 ; 2449$ men and 2645 women). Model 1, crude model. Model 2, adjusted for age, physical activity, education, ethnicity, alcohol consumption, coffee consumption and smoking. Women are additionally adjusted for menopausal status and use of hormones. Reference group, $61.2 \%$ women, $76.4 \%$ men; PSQI $>5,38.9 \%$ women, $23.6 \%$ men; PSQI $\geq 8,21.7 \%$ women, $11.2 \%$ men. 
Supplement Table 1: Characteristics of 1,947 participants who underwent MRI and completed the PSQI questionnaire in the NEO study, and stratified by sex.

\begin{tabular}{|c|c|c|c|}
\hline Characteristics & Total population & $\begin{array}{c}\text { Women } \\
(53 \%)\end{array}$ & $\begin{array}{l}\text { Men } \\
(47 \%)\end{array}$ \\
\hline Age (years) & $56(6)$ & $55(6)$ & $55.9(6)$ \\
\hline $\mathrm{BMI}\left(\mathrm{kg} / \mathrm{m}^{2}\right)$ & $26(4)$ & $25(4)$ & $26.4(3)$ \\
\hline Total body fat (\%) & $30(8)$ & $35.7(6)$ & $24.3(5)$ \\
\hline Waist circumference $(\mathrm{cm})$ & $90(12)$ & $84(12)$ & $97(10)$ \\
\hline $\operatorname{VAT}\left(\mathrm{cm}^{2}\right)$ & $76(47,116)$ & $54(36,84)$ & $101.4(73,140)$ \\
\hline Total sleep-duration (hours/night) & $7(1)$ & $7(1)$ & $7(1)$ \\
\hline Pittsburgh score & $4(3,6)$ & $5(3,7)$ & $4(2,5)$ \\
\hline Education $\left(\%\right.$ high $\left.^{\mathrm{a}}\right)$ & $47 \pm 1.1$ & $43 \pm 1.6$ & $51 \pm 1.6$ \\
\hline Ethnicity (\% white) & $96 \pm 0.4$ & $95 \pm 0.7$ & $96 \pm 0.6$ \\
\hline Alcohol consumption (g/day) & $10(3,21)$ & $8(2,15)$ & $17(5,28)$ \\
\hline Physical activity (MET-hours/week) & $31(16,52)$ & $30(16,51)$ & $32(16,54)$ \\
\hline \multicolumn{4}{|l|}{ Coffee consumption ${ }^{\mathrm{b}}$} \\
\hline - $\quad 0$ cups/day & $5 \pm 0.5$ & $7 \pm 0.8$ & $2 \pm 0.4$ \\
\hline - $\quad>0-4 \mathrm{cups} / \mathrm{day}$ & $59 \pm 1.1$ & $66 \pm 1.6$ & $51 \pm 1.6$ \\
\hline - $\quad>4$ cups/day & $37 \pm 1.1$ & $27 \pm 1.5$ & $47 \pm 1.6$ \\
\hline \multicolumn{4}{|l|}{ Smoking } \\
\hline - Current & $14 \pm 0.8$ & $13 \pm 1.1$ & $15 \pm 1.1$ \\
\hline - Former & $46 \pm 1.3$ & $45 \pm 1.6$ & $46 \pm 1.6$ \\
\hline Use of hypnotics and sedatives & $3 \pm 0.4$ & $4 \pm 0.6$ & $2 \pm 0.4$ \\
\hline \multicolumn{4}{|l|}{ Hormone use ${ }^{c}$} \\
\hline - Current & - & $9 \pm 0.9$ & - \\
\hline - Former & - & $82 \pm 1.3$ & - \\
\hline Post-menopausal state (\%) & - & $58 \pm 1.6$ & - \\
\hline
\end{tabular}

Results were based on analyses weighted towards the BMI distribution of the general population ( $\mathrm{n}=1947 ; 1032$ men, 915 women). Data are shown as mean (SD), median (IQR) or percentage $\pm 95 \%$ confidence interval for measurement dispersion.

BMI: Body Mass Index; MET: metabolic equivalent; NEO: Netherlands Epidemiology of Obesity; VAT: visceral adipose tissue; SAT: abdominal subcutaneous adipose tissue.

${ }^{a}$ High education: High education: higher general secondary education, pre-university education, higher vocational education, university.

${ }^{\mathrm{b}}$ Coffee cup defined as $125 \mathrm{ml} / \mathrm{cup}$.

${ }^{c}$ Hormone use: use of sex hormones, either oral contraceptives or hormone replacement therapy 
Supplementary Table 2: Associations between sleep duration and BMI, WC and TBF in 1,947 participants in the NEO study aged between 45 and 65 years. The study population is grouped according to sleep duration

\begin{tabular}{|c|c|c|c|c|c|}
\hline & $\begin{array}{c}\text { Shortest sleep } \\
(0-10 \%) \\
\text { Men }=1.7-5.7 \mathrm{hrs} \\
\text { Women }=2.9-5.4 \mathrm{hrs}\end{array}$ & $\begin{array}{c}\text { Short sleep } \\
(10-20 \%) \\
\text { Men }=5.7-6.0 \mathrm{hrs} \\
\text { Women }=5.4-5.9 \mathrm{hrs} \\
\end{array}$ & $\begin{array}{c}\text { Reference } \\
(20-80 \%) \\
\text { Men }=6.0-7.7 \mathrm{hrs} \\
\text { Women }=5.9-7.9 \mathrm{hrs} \\
\end{array}$ & $\begin{array}{c}\text { Long sleep } \\
(80-90 \%) \\
\text { Men }=7.7-8.0 \mathrm{hrs} \\
\text { Women }=7.9-8.0 \mathrm{hrs} \\
\end{array}$ & $\begin{array}{c}\text { Longest sleep } \\
(90-100 \%) \\
\text { Men }=8.0-10.8 \mathrm{hrs} \\
\text { Women }=8.0-10.9 \mathrm{hrs}\end{array}$ \\
\hline \multicolumn{6}{|c|}{ Body mass index $\left(\mathrm{kg} / \mathrm{m}^{2}\right)$} \\
\hline Men, model 1 & $1.2(0.3,2.1)$ & $-0.6(-1.5,0.4)$ & - & $-0.1(-0.9,0.8)$ & $-0.6(-1.6,0.3)$ \\
\hline Men, model 2 & $1.2(0.2,2.1)$ & $-0.7(-1.6,0.3)$ & - & $-0.0(-0.8,0.8)$ & $-0.9(-1.8,0.1)$ \\
\hline Women, model 1 & $1.7(-0.3,3.1)$ & $0.5(-0.8,1.7)$ & - & $-0.4(-1.4,0.5)$ & $0.4(-0.8,1.6)$ \\
\hline Women, model 2 & $1.4(-0.2,2.7)$ & $0.3(-0.9,1.4)$ & - & $-0.4(-1.3,0.5)$ & $0.1(-1.1,1.4)$ \\
\hline \multicolumn{6}{|c|}{ Waist circumference (cm) } \\
\hline Men, model 1 & $4.7(2.2,7.2)$ & $-0.2(-2.8,2.3)$ & - & $0.4(-2.5,3.3)$ & $-1.0(-3.8,1.7)$ \\
\hline Men, model 2 & $4.4(2.0,6.9)$ & $-1.0(-3.6,1.6)$ & - & $0.3(-2.4,3.0)$ & $-1.9(-4.7,0.9)$ \\
\hline Women, model 1 & $3.4(-0.7,7.6)$ & $2.4(-0.6,5.4)$ & - & $0.0(-2.9,2.9)$ & $1.3(-1.9,4.5)$ \\
\hline Women, model 2 & $2.5(-1.4,6.5)$ & $1.4(-1.6,4.4)$ & - & $0.0(-2.9,3.0)$ & $0.8(-2.6,4.3)$ \\
\hline \multicolumn{6}{|l|}{ Total body fat (\%) } \\
\hline Men, model 1 & $1.3(-0.1,2.8)$ & $-0.3(-1.7,1.1)$ & - & $-0.0(-1.5,1.5)$ & $-1.2(-2.8,0.3)$ \\
\hline Men, model 2 & $1.3(-0.1,2.7)$ & $-0.8(-2.3,0.6)$ & - & $-0.1(-1.4,1.2)$ & $-1.6(-3.2,-0.0)$ \\
\hline Women, model 1 & $1.6(-0.8,4.0)$ & $0.4(-1.5,2.3)$ & - & $-0.3(-2.2,1.7)$ & $-0.1(-2.1,1.9)$ \\
\hline Women, model 2 & $1.2(-1.0,3.4)$ & $-0.0(-1.8,1.8)$ & - & $-0.4(-2.4,1.6)$ & $-0.4(-2.5,1.7)$ \\
\hline
\end{tabular}

Results were based on analyses weighted towards the BMI distribution of the general population ( $\mathrm{n}=1947 ; 1032$ men, 915 women) and are

presented as the mean differences (with 95\% confidence interval) compared with the reference group. Model 1, crude. Model 2, adjusted for age,

physical activity, education, ethnicity, use of hypnotics and sedatives, alcohol consumption, coffee consumption and smoking. Models in women

were additionally adjusted for menopausal status and use of hormones. 
Supplementary Table 3: Associations between sleep-quality and BMI, WC and TBF in 1,947 participants in the NEO study aged between 45 and 65 years. The study population is grouped according to PSQI score.

\begin{tabular}{|c|c|c|c|}
\hline & $\begin{array}{l}\text { Reference } \\
(\mathrm{PSQI} \leq 5)\end{array}$ & $\begin{array}{c}\text { Poor sleep quality } \\
(\text { PSQI }>5)\end{array}$ & $\begin{array}{c}\text { Worse sleep quality } \\
\text { PSQI } \geq 8\end{array}$ \\
\hline \multicolumn{4}{|c|}{ Body mass index $\left(\mathrm{kg} / \mathrm{m}^{2}\right)$} \\
\hline Men, model 1 & - & $1.1(0.5,1.6)$ & $0.8(0.0,1.6)$ \\
\hline Men, model 2 & - & $1.0(0.4,1.6)$ & $0.8(0.1,1.6)$ \\
\hline Women, model 1 & - & $1.3(0.7,1.9)$ & $1.5(0.7,2.3)$ \\
\hline Women, model 2 & - & $1.2(0.6,1.8)$ & $1.5(0.7,2.2)$ \\
\hline \multicolumn{4}{|c|}{ Waist circumference (cm) } \\
\hline Men, model 1 & - & $3.5(1.7,5.3)$ & $2.2(-0.1,4.6)$ \\
\hline Men, model 2 & - & $3.4(1.6,5.1)$ & $2.2(-0.2,4.6)$ \\
\hline Women, model 1 & - & $3.1(1.2,5.0)$ & $3.8(1.4,6.2)$ \\
\hline Women, model 2 & - & $2.6(0.7,4.4)$ & $3.2(0.9,5.6)$ \\
\hline \multicolumn{4}{|l|}{ Total body fat (\%) } \\
\hline Men, model 1 & - & $1.5(0.5,2.5)$ & $1.0(-0.3,2.3)$ \\
\hline Men, model 2 & - & $1.5(0.5,2.5)$ & $1.1(-0.2,2.4)$ \\
\hline Women, model 1 & - & $1.7(0.5,2.8)$ & $2.1(0.6,3.6)$ \\
\hline Women, model 2 & - & $1.4(0.3,2.5)$ & $1.9(0.4,3.3)$ \\
\hline
\end{tabular}

Results were based on analyses weighted towards the BMI distribution of the general population ( $\mathrm{n}=1947$; 1032 men, 915 women). Results are presented as the mean differences (with 95\% confidence interval) compared to the reference group. Model 1, crude. Model 2, adjusted for age, physical activity, education, ethnicity, alcohol consumption, coffee consumption and smoking. Models in women were additionally adjusted for menopausal status and use of hormones. Reference group, $65.5 \%$ women, $77.5 \%$ men; PSQI $>5,34.5 \%$ women, $22.5 \%$ men; PSQI $\geq 8,19.8 \%$ women, $10.9 \%$ men. 